\title{
Anabases
}

ANABASES Traditions et réceptions de l'Antiquité

$25 \mid 2017$

Varia

\section{Malika BASTIN-HAMMOU et Charalampos ORFANOS (dir.), Carnaval et comédie}

\section{Alain Ballabriga}

\section{OpenEdition}

\section{Journals}

Édition électronique

URL : http://journals.openedition.org/anabases/6115

DOI : 10.4000/anabases.6115

ISSN : 2256-9421

\section{Éditeur}

E.R.A.S.M.E.

\section{Édition imprimée}

Date de publication : 1 avril 2017

Pagination : 273-274

ISSN : 1774-4296

\section{Référence électronique}

Alain Ballabriga, « Malika bastin-hammou et Charalampos orfanos (dir.), Carnaval et comédie », Anabases

[En ligne], 25 | 2017, mis en ligne le 01 avril 2017, consulté le 20 janvier 2021. URL : http://

journals.openedition.org/anabases/6115; DOI : https://doi.org/10.4000/anabases.6115

Ce document a été généré automatiquement le 20 janvier 2021.

(c) Anabases 


\title{
Malika BASTIN-HAMMOU et Charalampos ORfanos (dir.), Carnaval et comédie
}

\author{
Alain Ballabriga
}

\section{RÉFÉRENCE}

Malika BASTIN-HAMMOU et Charalampos ORFANOS (dir.), Carnaval et comédie,

Presses universitaires de Franche-Comté, 2015, 210 p.,

25 euros/ISBN 978-2-84867-540-4.

1 Ce volume présente les actes d'un colloque international organisé par l'équipe PLHCRATA les 9-10 décembre 2009 à l'Université de Toulouse - Le Mirail pour faire l'inventaire des acquis de la recherche actuelle trente ans après la parution de l'ouvrage Le Carnaval et la politique de Jean-Claude Carrière.

2 Après une introduction (p. 9-16) dans laquelle Malika Bastin-Hammou présente le livre de Jean-Claude Carrière, une première partie est constituée par une contribution de Ralph Rosen (p.19-33) qui revient sur les origines rituelles de la Comédie Ancienne. Alors que toutes les autres contributions admettent le caractère premier $\mathrm{du}$ " rire rituel » par rapport à la Comédie Ancienne, de même que l'univers carnavalesque médiéval préexiste à Rabelais, Ralph Rosen, à partir d'une analyse de l'épisode de Iambè dans l'hymne homérique à Déméter, pense pouvoir suggérer que l'obscénité rituelle est une imitation d'une forme d'interaction sociale qui existe dans le monde réel antérieurement à sa ritualisation plutôt que des injures visant à scandaliser et blesser. Il concède pourtant que nous n'avons aucun moyen de connaître l'effet de la moquerie rituelle sur les personnes visées et que le rituel pourrait être senti plus comme un théâtre séculier qu'un culte religieux, ce qui, à mon sens, affaiblit la portée de sa thèse.

3 Une deuxième partie intitulée «Utopie ? le corps et le langage comiques comme outils d'autonomie et d'ancrage de la comédie " comporte deux contributions. Dans la 
première, Ian Ruffell (p. 37-73) fait valoir que l'étude des vases montre une grande variabilité et souplesse du " corps comique " avec son phallos et des rembourrages. Par ailleurs, en s'opposant au costume tragique et aux représentations idéalisées des corps dans l'art (peinture, sculpture), le corps comique fait signe à sa façon vers les réalités et nécessités de la vie ordinaire. De son côté Pierre Judet de la Combe (p. 75-98) propose une analyse des Nuées visant à dépasser l'opposition entre lecture référentielle historique et interprétation plus libre, ludique (la comédie comme simple jeu fantaisiste). Selon lui, la comédie construit un modèle d'intelligibilité qui est référentiel non parce qu'il exprime ce que l'auteur pense sur la réalité du moment mais de manière indirecte et négative par la cohérence momentanée qu'il établit dans le spectacle face aux désordres de la réalité.

4 Une troisième partie intitulée "Comédie et tragédie : dialogisme et fonction critique " comporte quatre contributions. Dans la première, Rossella Saetta-Cottone (p. 101-114) suggère que le thème de l'accusation portée contre Euripide dans les Thesmophories reprend, en le réélaborant, le thème de l'accusation portée contre le poète comique tel qu'il est présenté dans les Acharniens, avec dans les deux cas une parodie du Télèphe d'Euripide. La contribution suivante revient sur le chœur des grenouilles dans les Grenouilles. Selon Angela Maria Andrisano (p.115-131), le chœur secondaire des grenouilles, dont la présence, à la différence du chœur principal des Initiés, est limitée au moment où Dionysos doit traverser le lac sur la barque de Charon, serait une parodie du nouveau dithyrambe et aurait une vraie présence scénique (chant et danse). Dans une troisième contribution, Ghislaine Jay-Robert (p. 133-146) étudie le thème de l'œil et sa mise en scène chez Aristophane. Elle en conclut que chez cet auteur l'œil et le regard ont des caractéristiques semblables à celles du masque comique. Contrairement à ce qui se passe dans la tragédie, le masque, sur une scène comique, n'entraîne pas dans le monde de l'autre, mais renvoie le spectateur à lui-même, en affichant son image transformée sur le mode grotesque. La dernière contribution de cette partie envisage la figure du barbare chez Aristophane. Suzanne Saïd (p. 147-158) fait valoir que la figure du barbare chez Aristophane est beaucoup moins complexe que chez Euripide. Leur portrait manque d'originalité et réaffirme simplement le fossé culturel séparant Grecs et Barbares, tandis que la définition de l'hellénisme met l'accent sur la langue et la culture.

5 La quatrième et dernière partie intitulée " Le politique vu d'ailleurs. Carnaval et politique dans la comédie antique après Aristophane » comporte deux études. Dans la première Christophe Cusset (p.161-177) fait état d'un mode de présence différent du politique chez Ménandre. Dans les Sicyoniens, on trouve ainsi une critique des assemblées populaires mise dans la bouche d'un oligarque tandis que l'opposition des prétendants repose aussi sur des critères politiques (oligarchie vs démocratie). Il y a de la sorte une dimension politique au sein d'une intrigue domestique et amoureuse. Quant à l'héritage carnavalesque, on pourrait encore en trouver un écho, très atténué, dans quelques insultes obscènes qu'échangent à l'occasion les personnages de Ménandre. La dernière étude de ce volume envisage la liberté de parole sur la scène comique à Rome au $\mathrm{e}^{\mathrm{er}}$ siècle avant J.-C. Selon Marie-Hélène Garelli (p. 179-195), à Rome, la tragédie, la comédie palliata (à la grecque), la togata (comédie à la romaine) ouvrent toutes le champ à une expression politique qui n'est pas, contrairement à ce que laissent entendre les textes, nécessairement populaire et spontanée, mais plutôt guidée par des factions aristocratiques et lettrées qui s'affrontaient aussi lors de joutes politiques et rhétoriques dans les autres lieux de la cité. Il n'y aurait donc pas une 
liberté de parole intrinsèque au genre du mime mais des joutes politiques publiques devant des spectateurs de théâtre. Mais l'auteur rappelle aussi que les témoignages relatifs à la liberté d'expression du chevalier et mimographe Labérius sont nombreux et significatifs.

6 Pour finir je me permettrais une remarque d'ordre général. Certains auteurs rappellent à juste titre le caractère dialogique, intertextuel et compétitif de la Comédie Ancienne. Or ce caractère se retrouve dans une partie des contributions de ce recueil, comme si les recherches sur la Comédie Ancienne imitaient leur objet. On a affaire à un champ d'études de plus en plus complexe et varié, sinon contradictoire, où des spécialistes s'adressent à d'autres spécialistes au courant des arcanes de la recherche contemporaine. On tend ainsi à s'éloigner de l'ouvrage pionnier de Jean-Claude Carrière qui reste, lui, aisément accessible à tous les hellénistes, voire aux lettrés curieux de théâtre antique.

\section{AUTEURS}

\section{ALAIN BALLABRIGA}

Directeur de recherches honoraire (CNRS)

a.ballabriga@gmail.com 